\title{
PROTOGYNOUS DICHOGAMY, LEAF MORPHOLOGY AND LEAF ESSENTIAL OIL COMPOSITION OF SELECTED Cinnamomum SPECIES IN SRI LANKA
}

\author{
MR Prathibhani ${ }^{1}$, RAAK Ranawaka ${ }^{2}$, AR Samantha $^{3}$, Sudarshanee Geekiyanage ${ }^{4 *}$ \\ ${ }^{1}$ Faculty of Graduate Studies, University of Ruhuna, Matara, Sri Lanka \\ ${ }^{2}$ Department of Export Agriculture, Peradeniya, Sri Lanka \\ ${ }^{3}$ Department of Chemistry, University of Ruhuna, Matara, Sri Lanka
}

Received: 23 May 2021: Accepted: 18 August 2021

\begin{abstract}
Wild relatives of cultivated cinnamon (Cinnamomum verum J. Presl) are underutilized and endangered in Sri Lanka. There is a lack of knowledge on wild relatives of cinnamon, hampering their utilization in breeding and industry. Morphology, floral behaviour and leaf essential oil composition of selected wild relatives were determined under ex-situ conservation in Dalpitiya, Sri Lanka. Floral cycles were determined in Cinnamomum dubium Nees $(C d)$ and Cinnamomum litsaeifolium Thwaites $(C l)$ along with Cinnamomum verum $(C v)$ variety $S r i$ Gemunu (SG). $C l$ and $S G$ belonged to type A, while $C d$ was type B of protogynous dichogamy. Partial overlapping of male and female phases in types $A$ and $B$ may lead to self-pollination. Leaf morphological characters varied among species. Gas Chromatography Mass Spectrometry revealed 34, 34, 12, 48, 8 and 18 chemical compounds from Cinnamomum capparu-coronde Blume (Cc), $C d, C l(1), C l(2), S G$ and variety $S r i$ Wijaya (SW) respectively. The highest abundant chemical compound in leaf oil varied as Eugenol in $C c, S G$ and $S W(33.11 \%, 82.11 \%$ and $90.80 \%$ respectively), Methyl eugenol in $C l(1)(59.27 \%)$, Eucaliptol in $C d(51.19 \%)$ and Linalool in $C l(2)$ $(30.93 \%)$. The above variation of wild cinnamon provides insights on future cinnamon breeding and industry.
\end{abstract}

Keywords: Chemical Composition, Cinnamomum capparu-coronde Blume, Cinnamomum dubium Nees, Cinnamomum litsaeifolium Thwaites, Floral behaviour

\section{INTRODUCTION}

Genus Cinnamomum of Family Lauraceae consists of about 250 species and sub-species grown in South and Central America, Asia and Australia (Mabberley 2008). The true cinnamon produced from the cultivated species, Cinnamomum verum J. Presl $(C v)$ is one of the most important spices in the world. Sri Lanka is the world's largest true cinnamon producer. Cinnamomum dubium Nees $(C d)$ (Sewel Kurundu in Sinhala), Cinnamomum ovalifolium Wight (Wal Kurundu or Bola Kurundu in Sinhala), Cinnamomum litsaeifolium Thwaites $(C l)$ (Kudu Kurundu in Sinhala), Cinnamomum rivulorum Kosterm

\footnotetext{
*Corresponding author: sudarshanee@agbio.ruh.ac.lk
}

(Wal Kurundu in Sinhala), Cinnamomum sinharajaense Kosterm (Sinharaja Kurundu in Sinhala), Cinnamomum capparu-coronde Blume (Cc) (Kapuru Kurundu in Sinhala) and Cinnamomum citriodorum Thwaites (Pangiri Kurundu in Sinhala) are the crop wild relatives of Sri Lankan cultivated cinnamon (Kumarathilake et al. 2010). Except for $C l, C d$ and Cinnamomum ovalifolium Wight, other species are considered to be endemic to Sri Lanka. $\mathrm{Cl}$ and Cinnamomum ovalifolium Wight are native to India and Sri Lanka and $C d$ is considered to be native to Myanmar and Sri Lanka (Plants of the World Online 2021). Kumarathilake et al. (2010) had carried out an eco-geographic survey determining the 
extinction risk level of wild cinnamon species in Sri Lanka. According to Kumarathilake (2009), Cinnamomum citriodorum, Cinnamomum rivulorum, Cinnamomum sinharajaense, $C c$ and $C l$ are critically endangered at the global level. Cinnamomum citriodorum and $C c$ are highly threatened at the national level. $C c$ is distributed in low country rain forests. $\mathrm{Cl}$ is a threatened species at the national level and is only found in the Knuckles forest of Sri Lanka. $C d$ with medicinal and timber value is not a threatened species and is grown in tropical rain forests and secondary forests in Sri Lanka. Habitat destruction for urbanization and intensive agricultural practices had been identified as the major threats to wild cinnamon species in Sri Lanka by Kumarathilake (2009), who had proposed conservation strategies such as the declaration of restricted areas, in-situ management in forest reservations and development of new policies. The ex-situ conservation sites of wild cinnamon species established by Kumarathilake (2009) in Sri Lanka, are at Kanneliya forest reserve, Royal Botanical Garden in Peradeniya, Horticultural Research and Development Institute in Gannoruwa, Faculty of Agriculture, University of Ruhuna in Kamburupitiya and Mid Country Research Station, Department of Export Agriculture in Dalpitiya, Bandaranayake Memorial Ayurveda Research Institute in Nawinna, Forest Department Research Station in Badulla and Barbarian Beach Resort in Weligama. However, these ex-situ conservation sites consist of heterogenous plant collections as seedlings from exploration sites had been used for the establishment. During his study, $C c$, Cinnamomum citriodorum and $C d$ were identified as potential candidates for $C v$ breeding. Among them, $C c$ was identified as the most suited species for domestication due to its desirable characters of the high amount of eugenol in leaf essential oil, the erect stem and medicinal and timber value. However, Kumarathilake (2009) reported that the above species were not successful in vegetative propagation. Prathibhani et al. (2020) reported the variation of shoot regeneration capacity of stem cuttings from several $C v$ genotypes. Geethakumary et al. $(2007 ; 2012)$ reported the distribution of $C d$ and $C l$ in the southern part of
Western Ghats, India while Ananthakrishnan et al. (2018) reported the variation of the chemical composition of several Cinnamomum species found in the Western Ghats, India including $C l$ and $C d$. There are no reports on genetic relatedness among Sri Lankan and Indian $C l$ and $C d$ genotypes. Yang et al. (2019) proposed an identification method for morphologically similar Cinnamomum species using leaf images and deep convolutional neural networks classifiers with 96.7\% test accuracy. Ho and Hung (2011) proposed inter-simple sequence repeats (ISSRs) and ribosomal DNA internal transcribed spacer (ITS) molecular markers to identify the cladistic relationship of 12 endemic Cinnamomum species in Taiwan. Ho et al. (2015) reported the use of the same ITS for authentication of Cinnamomum osmopholoeum and related species in Taiwan. Azad et al. (2016; 2019a; 2019b) carried out a detailed study on $C v$ germplasm in Sri Lanka with the assistance of the Department of Export Agriculture, Sri Lanka. Morphologically different 269 cinnamon accessions were selected for the study from more than 3000 cinnamon plants in 51 farmer fields located in major cinnamon growing areas in Sri Lanka. The same team (Team of TURIS 2013 project) developed a set of descriptors for cinnamon based on the observed morphological variation of Sri Lankan $C v$ germplasm during the study. Variation of leaf and flower morphology and bark chemical composition of $C v$ germplasm under the in-situ conditions in Sri Lanka was reported by Azad et al. (2016; 2018; 2019a and Unpublished data). Azad et al. (2019a) established a vegetatively propagated collection of above 269 cinnamon accessions at the Faculty of Agriculture, University of Ruhuna. Variations of leaf morphology and leaf essential oil composition of the above collection at the Faculty of Agriculture revealed the genetic diversity of $\mathrm{Cv}$ germplasm in Sri Lanka (Prathibhani et al. 2019).

The leaf is one of the most useful morphological characters in genus Cinnamomum as it is highly varied among species (Ravindran et al. 2004). 
Kumarathilake (2009) had classified Cinnamomum species using a key based on the in-situ variation of leaf and bark morphological characters.

In Family Lauraceae, protogynous dichogamy is observed: Flowers open in two phases, where the female phase is prior to the male phase. The first opening of flowers occurs during the morning in the type A plants, while it occurs during noon in type B plants. At the first phase only, the stigma appears as receptive. The first and third stamen whorls appear fused during this stage. First opening lasts for about five hours. The second phase begins after 24 hours of first opening. The third whorl of the stamens adheres to the pistil. The anthers become dehiscent after 1/21 hour of second opening. The stigma is shriveled and become non-receptive. Again, the flower is kept open for about five hours (Joseph 1981; Kubitzski and Kurz 1984; Sedgley and Griffin 1989). According to Azad et al. (2018), there is a variation in inflorescence as in panicle length, panicle type, flower colour, flower length, flower width, tepal length, tepal width, tepal number and tepal pubescence within $C v$ germplasm. Information on inflorescence type, size and flower colour of fifteen accessions from a field survey conducted in 15 locations of cultivated lands and wild habitats in Matara district, Sri Lanka has been reported by Azad et al. (2018). The same authors suggested the possible linkage between large flower size and type A flower behaviour.

There may be inter-species variation in the time of occurrence and active duration of the female and male phases among Cinnamomum species. Protogynous dichogamy, which leads to cross-pollination, contributes to allele richness in $C v$ germplasm (Azad et al. 2015). Bark, leaf, root and fruit essential oils of $C v$ bear each of unique chemical profiles has majored with cinnamaldehyde, eugenol, camphor and cadinene respectively (Senanayake et al. 1989; Paranagama et al. 2001). $C v$ possesses antidiabetic, anticholinergic, antilipidemic, antiinflammatory, antioxidant, anticarcinogenic, antimicrobial and insecticidal properties
(Ranasinghe et al. 2012; Ranasinghe and Galappaththy 2016; Abeysekera et al. 2017; Gulcin et al. 2019; Unlu et al. 2010; Kim et al. 2015). Many traditional Asian cultures use cinnamon in bloating, nausea, flatulence, colic and gastro-intestinal tract spastic conditions (Toriizuka 1998). There is unpublished information on the use of wild cinnamon species for medicinal purposes in Sri Lanka. Kumarathilake (2009) reported the in-situ chemical compositional variation of $C c$ and $C d$ through Gas Liquid Chromatography (GLC) analysis.

The genetic diversity of wild cinnamon germplasm in Sri Lanka would be depicted through environment-independent leaf morphological variation. The wide chemical profiles of wild cinnamon species in Sri Lanka would be potential sources in food, pharmaceuticals and cosmetics. Revealing the extent of protogynous dichogamy among wild cinnamon would be useful in their utilization in breeding programmes.

One plant of $C c$, one plant $C d$ and two plants of $\mathrm{Cl}$ through the exploration of Kumarathilake (2009) were maintained in the ex-situ conservation site at Mid Country Research Station. Seed setting had been observed at the above ex-situ conservation site in 2018 by the second author. As there were single plants of $C c, C d$ and two plants of $C l$ (named as $\mathrm{Cl}-1$ and $\mathrm{Cl}-2$ ) at the site, we speculated that selfing within the single plant or cross-pollination with another Cinnamomum spp. had taken place.

Therefore, this study was conducted in the following year (2019) to determine the morphological and chemical characters and flower type of each spp. as such information would be useful in identifying potential hybrids in the future. Further, the information on essential oil composition would be useful in industrial applications.

\section{MATERIALS AND METHOD}

The present study was based on the ex-situ wild cinnamon conservation site at MidCountry Research Station, Department of Export Agriculture, Dalpitiya (WM2) (GPS: 
$7.1333031 \mathrm{~N}, 80.590026$ E) established by Kumarathilake (2009). Observations on flowering of above Cinnamomum spp. were made. According to the availability of flowers during the study period of February to March 2019, the floral behaviour of two wild cinnamon species of $C d$ and $C l$ along with $S G$ was determined. Floral cycles were determined through visual observation of flowers for two consecutive days from 8 am to $4 \mathrm{pm}$. Leaf morphology and leaf essential oil composition of wild cinnamon species of $C c, C d$ and $C l$ along with $S G$ and $S W$ were determined. Mature leaves of one $C d$, one $C c$, two $C l$ (1), (2), $S G$ and $S W$ were collected randomly at $5^{\text {th }}$ to $6^{\text {th }}$ leaf from the tip of the branch for both morphological characterization and leaf essential oil analysis. Length, width and petiole length were measured as quantitative leaf morphological characters. Qualitative leaf morphological characters of shape, apex, base, texture, venation and margin were characterized using the Descriptors for Cinnamon (Team of TURIS 2013 Project 2016). The leaf essential oil was extracted using the hydro-distillation method and analyzed using Gas Chromatography Mass Spectrometry (GCMS).

\section{RESULTS AND DISCUSSION}

There was a variation in leaf morphological characters of leaf length, leaf width, leaf shape, leaf apex, leaf base, leaf texture, leaf venation, petiole length and leaf margin among Cinnamomum species (Table 1, Figure 1). $C c$ and $C d$ were lanceolate leaf-shaped while $C l$ (1) and $C l$ (2) were elliptic leafshaped. $S G$ and $S W$ were broadly ovate and ovate leaf-shaped respectively. $\mathrm{Cl}$ (1), (2), $S G$ and $S W$ had acute leaf apexes. $C c$ and $C d$ leaf apexes were acuminate with broad acumen and long acuminate respectively. Leaf base of $C d, S G$ and $S W$ was round. $C c, C d$ and $C l(1)$ leaf textures were thin to stiffly coriaceous. $S G$ and $S W$ had the same chartaceous leaf

Table 1: Leaf morphological characters of $C c, C d, C l(1), C l(2), S G$ and $S W$

\begin{tabular}{llllllllll}
\hline Species & & \multicolumn{9}{c}{ Leaf character* } \\
& LL $(\mathrm{cm})$ & LW $(\mathrm{cm})$ & LS & LA & LB & LT & LV & PL $(\mathrm{cm})$ & LM \\
\hline $\boldsymbol{C} \boldsymbol{c}$ & $13.98 \pm 1.44$ & $4.20 \pm 0.67$ & 7 & 6 & 2 & 4 & 3 & $1.00 \pm 0.24$ & 1 \\
$\boldsymbol{C d}$ & $12.52 \pm 1.53$ & $3.78 \pm 0.50$ & 7 & 4 & 4 & 4 & 3 & $0.66 \pm 0.21$ & 1 \\
$\boldsymbol{C l}(\mathbf{1})$ & $7.88 \pm 1.24$ & $2.88 \pm 0.40$ & 1 & 1 & 6 & 4 & 1 & $1.10 \pm 0.17$ & 1 \\
$\boldsymbol{C l}(\mathbf{2})$ & $7.44 \pm 0.44$ & $2.66 \pm 0.23$ & 1 & 1 & 7 & 5 & 1 & $0.88 \pm 0.21$ & 1 \\
$\boldsymbol{S G}$ & $14.02 \pm 2.13$ & $6.68 \pm 1.13$ & 5 & 1 & 4 & 6 & 3 & $1.60 \pm 0.26$ & 1 \\
$\boldsymbol{S W}$ & $11.88 \pm 1.22$ & $5.92 \pm 0.64$ & 4 & 1 & 4 & 6 & 1 & $1.16 \pm 0.21$ & 2 \\
\hline
\end{tabular}

*According to the Descriptors for Cinnamon (Team of TURIS, 2013 project) LL: Leaf length; LW: Leaf width; LS: Leaf shape 1-Elliptic, 4-Ovate, 5-Broadly ovate, 7-Lanceolate; LA: Leaf apex 1-Acute, 4-Long acuminate, 6-Acuminate with broad acumen; LB: Leaf base 2-Subacute, 4-Rounded, 6-Obtuse, 7-Obtuse, contracted into petiole, then shortly cuneate; LT: Leaf texture 4-Thinly to stiffly coriaceous, 5-Chartaceous to rigidly chartaceous, 6-Chartaceous; LV: Leaf venation 1-Three veined, 3-Three veined or Five veined; PL: Petiole length; LM: Leaf margin

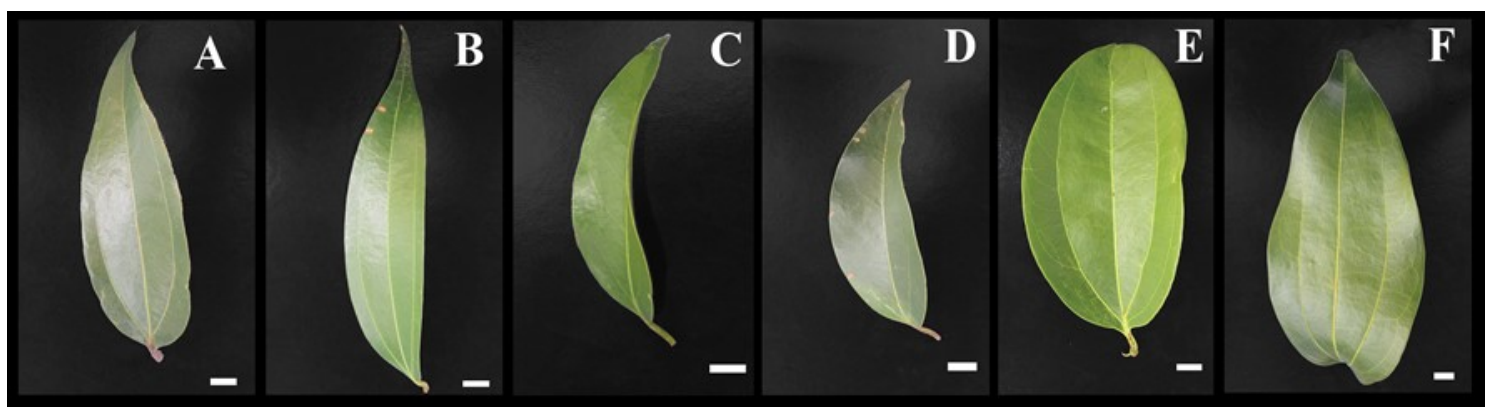

Figure 1: Leaves of wild and cultivated cinnamon

$C c: \mathrm{A} ; C d: \mathrm{B} ; C l(1): \mathrm{C} ; C l(2) ; \mathrm{D} ; S G$ : E; $S W: \mathrm{F}$ (Scale: $1 \mathrm{~cm})$ 
texture, while $\mathrm{Cl}$ (2) was of chartaceous to rigidly chartaceous leaf texture. $\mathrm{Cl}(1),(2)$, $S G$ and $S W$ had three-veined leaves while $C c$ and $C d$ had three-veined or five veined leaves. All $C c, C d, C l(1),(2)$ and $S G$ had the entire leaf margin. $S W$ was with the undulate leaf margin.

We observed wild cinnamon flowering from February to March 2019 in Dalpitiya. Sri Lanka. The flowering season of $C v$ begins in November and continues until early March. $C v$ fruits ripen from May to June (Joseph 1981; Kubitzki and Kurz 1984; Mohankumar et al. 1985). According to our observations in Southern Sri Lanka, $C v$ flowering starts from August to September and extends up to April in the following year. There are evidences that the floral behaviour of cinnamon might be affected by the environmental factors of day length, photon flux density and
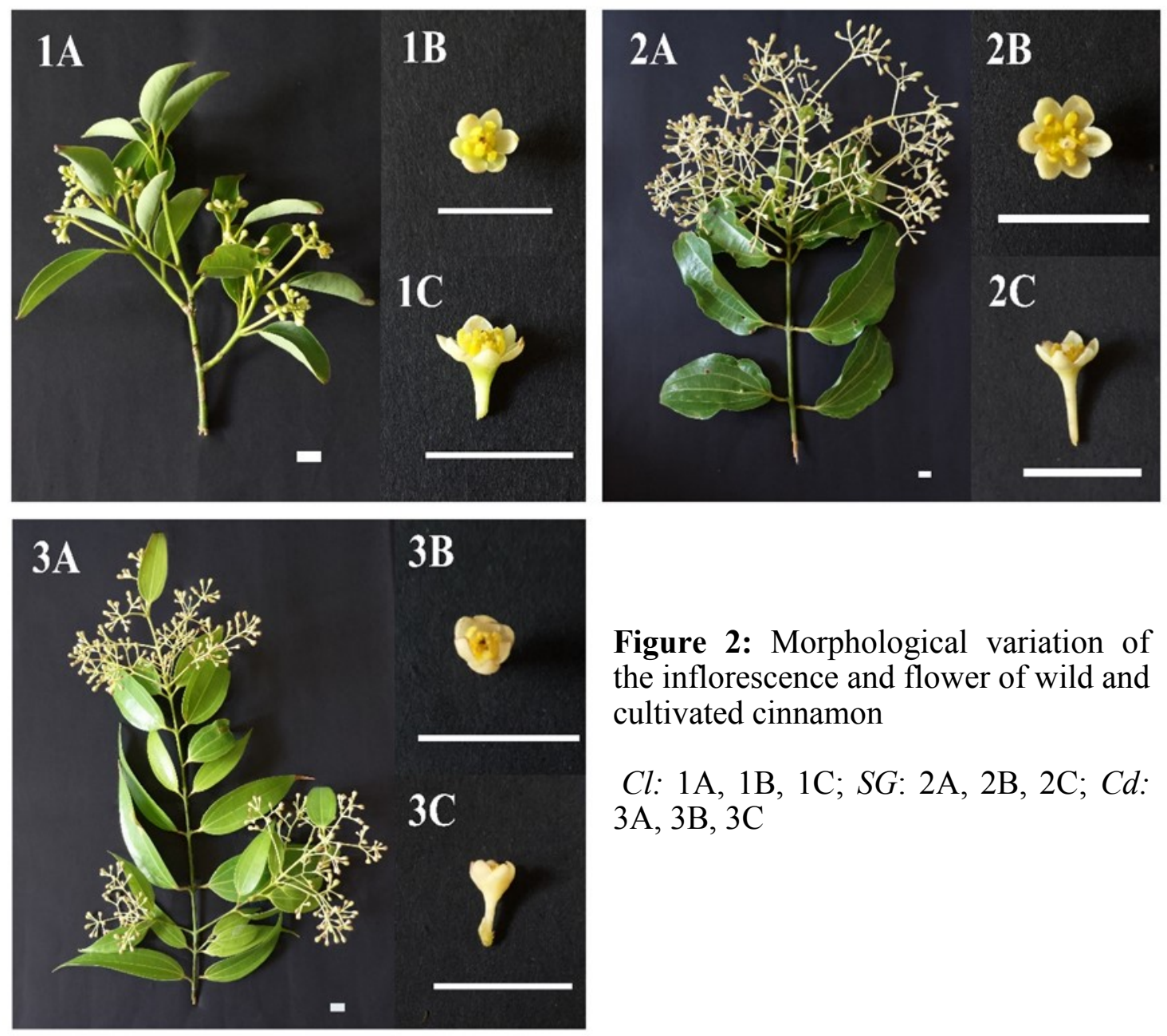

Figure 2: Morphological variation of the inflorescence and flower of wild and cultivated cinnamon

$C l: 1 \mathrm{~A}, 1 \mathrm{~B}, 1 \mathrm{C} ; S G: 2 \mathrm{~A}, 2 \mathrm{~B}, 2 \mathrm{C} ; C d$ : $3 \mathrm{~A}, 3 \mathrm{~B}, 3 \mathrm{C}$ temperature (Sedgley 1985). According to Schaffer and Anderson (2018), the floral induction of avocado was not directly influenced by day length, while day length determined the floral behaviour of protogynous dichogamy. The floral cycle of the avocado was completely disrupted under continuous light conditions as the male phase and female phase flowers were open throughout the day and the shorter day lengths shortened its floral cycle (Sedgley 1985).

All $C l, S G$ and $C d$ produced axillary panicles (Figure 2). $C l$ and $C d$ produced equally dense panicles at the axil and the apex. $S G$ panicles got long peduncles and were dense at the apex of the branchlets. According to the visual observation of inflorescences and individual flowers of three Cinnamomum spp, the inflorescences carried flowers and buds of different physiological maturity (Figure 2). 
The inflorescence of the variety $S G$ was large and produced a comparatively large number of flowers while $C d$ and $C l$ inflorescences were small in size with a small number of flowers (Figure 2). Immature and mature unopened flowers of $C d$ were pinkish-yellow while $C l$ and $S G$ were yellowish-green.

The morphology of flowers of all three species in Figure 2, was in accordance with the previous records on typical $C v$ flowers (Azad et al. 2018; Heslop-Harrison and Shivanna 1977) and on typical Lauraceae flowers by Zeng et al (2017). The standard floral characters comprise of six tepals in two whorls and fifteen stamens in three whorls; both whorl I and whorl III contain six stamens, while whorl II contains only three stamens. A style arises from the ovary. Three staminal glands are present in between stamen whorl II and the stigma (Azad et al. 2018).

In $S G$ and $C l$, the inflorescence produced open flowers of two physiological stages during the morning. Flowers of one of the stages opened from 8.00 to 9.00 am with white colour stigma. They remained open around five hours till $1.00 \mathrm{pm}$ and closed. They opened again on the next day around 11.00 am with brown colour stigma and tepals. After about five hours they permanently closed completing the floral cycle. According to the classification of flowers on dichogamy, variety $S G$ and the studied $\mathrm{Cl}$ plant are included under type-A.

The studied $C d$ plant belonged to the type-B category. The flowers started opening in the afternoon around $1.00 \mathrm{pm}$ with fresh white colour stigma and tepals. The stamen whorls appeared as fused. They remained opening about $3 \frac{1}{2}$ hours and closed around $4.00 \mathrm{pm}$. They opened again on the next day around $8.00 \mathrm{am}$. There were anthers dehiscent with pollens around 9.00-10.00 am. They were with brown colour stigma and brown colour tepals at this opening and remained open about 7 hours. According to the above observations, partial overlapping of functional male and functional female stages may lead to self-pollination in all three species.
Joseph (1981) reported that the female and male phases of cinnamon flowers separated by almost one day. According to our observations in Dalpitiya, Sri Lanka, the above observation was confirmed for the type A plants. The floral cycle of type B plants consisted of the female and male phases separated by twelve hours. In accordance with the report of Mohankumar et al. (1985), we also observed the maximum flower breath at the second phase of the floral cycle.

There are reports on the presence of type A and type B plants in $C v$ and $C$. camphora populations. Within a $C v$ population, $3 / 5$ of the plants are type $A$ and $2 / 5$ of the plants are type B (Joseph 1981). In a natural population, $A$ and $B$ plant types are mixed for the availability of functional male and female flowers at any given time (Joseph 1981; Kubitzski and Kurz 1984). The majority of cultivars belong to type B among the studied ten cultivars of $C v$ for floral behaviour at the National Cinnamon Research and Training Center, Sri Lanka (Kumari et al. 2008). There is some unpublished information on floral behavior of two commercial varieties of $C v$ in Sri Lanka as $S G$ is type A and $S W$ is type B. Future work should be focused on the molecular basis of type A and type B plants of cinnamon, floral morphological markers for identifying the two types of plants and the environmental effects on floral behaviour of cinnamon.

There were 122 chemical compounds in $C c$, $C d, C l(1),(2), S G$ and $S W$ (Table 2). A total of $34,34,12,48,8$ and 18 chemical compounds were detected from $\mathrm{Cc}, \mathrm{Cd}, \mathrm{Cl}$ (1), (2), $S G$ and $S W$ respectively. Eugenol was the major chemical compound of leaf essential oils from $C c(33.11 \%), S G$ and $S W$ ( $82.11 \%$ and $90.80 \%$ respectively). Other than eugenol, $11.76 \%$ of linalool, $15.93 \%$ of methyl palmitate and $20.04 \%$ of methyl elaidate were reported in $C c$. There were $2.36 \%$ of linalool, $4.68 \%$ of caryophyllene and $9.55 \%$ of eugenyl acetate in $S G$. There were $4.94 \%$ of linalool and $2.32 \%$ of caryophyllene in $S W$. Eucalyptol was the major chemical compound of $C d(51.19 \%)$. With eucalyptol, $C d$ got $13.18 \%$ of alpha- 
Table 2: Chemical composition of leaf essential oil of wild and cultivated cinnamon

\begin{tabular}{|c|c|c|c|c|c|c|c|}
\hline & Chemical compound & $C c$ & $C d$ & $\mathrm{Cl}(1)$ & $C l(2)$ & $S G$ & $S W$ \\
\hline 1 & Eucalyptol & - & 51.19 & - & 0.12 & - & 0.097 \\
\hline 2 & Linalool & 11.761 & 3.406 & 7.163 & 30.93 & 2.362 & 4.939 \\
\hline 3 & $\begin{array}{l}\text { 1-H-indazole, 4,5,6,7-tetrahydro-7- } \\
\text { methyl }\end{array}$ & - & - & - & - & - & - \\
\hline 4 & Isoborneol & 0.075 & - & - & - & - & - \\
\hline 5 & 4-Terpinenyl acetate & - & - & - & 0.208 & - & - \\
\hline 6 & alpha-Terpineol & 0.367 & $\begin{array}{c}13.18+0.7 \\
2\end{array}$ & 0.63 & 10.013 & - & 0.27 \\
\hline 7 & delta-Cadinene & - & 0.078 & 0.392 & - & - & - \\
\hline 8 & alpha-Amorphene & - & - & 0.136 & 0.714 & - & - \\
\hline 9 & Pentane, 3-methylene & 0.064 & - & - & - & - & - \\
\hline 10 & delta-Elemene & 0.078 & - & - & - & - & - \\
\hline 11 & Eugenol & 33.105 & - & 24.993 & - & 82.107 & 90.80 \\
\hline 12 & Benzene, 1,2,4-triethyl & 2.206 & - & - & - & - & - \\
\hline 13 & Cyclohexene, 1-butyl & 0.304 & - & - & - & - & - \\
\hline 14 & Caryophyllene & 1.818 & - & - & 3.044 & 4.682 & 2.316 \\
\hline 15 & $\begin{array}{l}\text { 1,4,7,-Cycloundecatriene, } 1,5,9,9- \\
\text { tetramethyl-,Z,Z,Z }\end{array}$ & 0.264 & - & 0.159 & - & - & 0.264 \\
\hline 16 & $\begin{array}{l}\text { 1H-Cycloprop[e]azulene, decahydro- } \\
\text { 1,1,7-trimethyl-4methylene-,[1aR- } \\
\text { (1a.alpha.,4a.beta.,7.alpha.,7a.beta., } \\
\text { 7b.alpha.)] }\end{array}$ & $\begin{array}{c}0.216+ \\
0.212\end{array}$ & - & - & - & - & 0.05 \\
\hline 17 & trans-isolongifolene & 0.062 & - & - & - & - & - \\
\hline 18 & Copaene & 0.074 & - & 2.243 & $\begin{array}{c}0.555+ \\
0.931\end{array}$ & - & - \\
\hline 19 & beta-Gurjunene & 0.136 & - & - & - & - & - \\
\hline 20 & 5-Muuroladiene & 0.098 & - & - & - & - & - \\
\hline 21 & Bicyclogermacrene & 0.331 & - & - & - & - & - \\
\hline 22 & alpha-Muurolene & 0.188 & - & - & 0.597 & - & - \\
\hline 23 & delta-Cadinene & 1.116 & - & - & $\begin{array}{c}1.181+ \\
3.583\end{array}$ & - & 0.052 \\
\hline 24 & $\begin{array}{l}\text { a-Triazolo[4,3-a]pyridine, } 3,5,7- \\
\text { trimethyl- }\end{array}$ & 0.054 & - & - & - & - & - \\
\hline 25 & 3-Undecen-1-yne, (E) & 0.083 & - & - & - & - & - \\
\hline 26 & $\begin{array}{l}\text { Cyclopentanecarboxamide, N-(2- } \\
\text { fluorophenyl)- }\end{array}$ & 1.71 & - & - & - & - & - \\
\hline 27 & Espatulenol & 0.787 & - & - & - & - & - \\
\hline 28 & beta-Selinene & 0.732 & - & - & - & - & - \\
\hline 29 & $\begin{array}{l}\text { Bicyclo[5,2,0]nonane, } 4,8,8- \\
\text { trimethyl-2-methylene }\end{array}$ & 0.14 & - & - & - & - & - \\
\hline 30 & 3-Hexyne & 0.333 & - & - & - & - & - \\
\hline 31 & Cadinadiene-1,4 & 0.528 & - & - & - & - & - \\
\hline 32 & gamma-Cadinene & $\begin{array}{c}0.856+ \\
0.228\end{array}$ & - & - & - & - & - \\
\hline 33 & Cyclohexene,1-methyl-3-vinyloxy- & 0.525 & - & - & - & - & - \\
\hline 34 & Methyl myristylate & 0.356 & - & - & - & - & - \\
\hline 35 & Phthalic acid, isobutyl undecyl ester & 0.217 & - & - & - & - & - \\
\hline
\end{tabular}




\begin{tabular}{|c|c|c|c|c|c|c|c|}
\hline & Chemical compound & $C c$ & $C d$ & $C l(1)$ & $\mathrm{Cl}(2)$ & $S G$ & $S W$ \\
\hline 36 & Methyl palmitate & 15.928 & - & - & 0.233 & - & - \\
\hline 37 & Methyl linoleate & 3.519 & - & - & - & - & - \\
\hline 38 & Methyl elaidate & 20.035 & - & - & - & - & - \\
\hline 39 & Methyl stearate & 1.494 & - & - & - & - & - \\
\hline 40 & 1R-alpha-Pinene & - & 1.361 & - & - & - & - \\
\hline 41 & (-)- 4-Terpineol & - & 5.421 & - & - & - & - \\
\hline 42 & alpha-Santalene & - & 4.583 & - & - & - & - \\
\hline 43 & 2-Norpinene & - & 2.64 & - & - & - & - \\
\hline 44 & Norbonane & - & $\begin{array}{c}2.955+ \\
3.610\end{array}$ & - & 0.163 & - & - \\
\hline 45 & beta-Bisabolene & - & 0.204 & - & - & - & - \\
\hline 46 & gamma.-Elemene & - & - & 0.167 & - & - & - \\
\hline 47 & Eugenyl acetate & - & - & - & - & 9.549 & - \\
\hline 48 & $\begin{array}{l}\text { 1,7,7-Trimethyl-2-vinylbicyclo } \\
{[2.2 .1] \text { hept-2-ene }}\end{array}$ & - & - & - & 9.057 & - & - \\
\hline 49 & alpha-Thujene & - & 0.222 & - & - & - & - \\
\hline 50 & Camphene & - & 0.051 & - & - & - & - \\
\hline 51 & beta-Thujene & - & 2.815 & - & - & - & - \\
\hline 52 & beta-Pinene & - & 1.552 & - & - & - & - \\
\hline 53 & beta-Myrcene & - & 0.077 & - & - & - & - \\
\hline 54 & alpha-Terpinene & - & 0.282 & - & & - & - \\
\hline 55 & m-Cymene & - & 0.633 & - & - & - & - \\
\hline 56 & gamma-Terpinene & - & $\begin{array}{c}0.711+ \\
0.192\end{array}$ & - & - & - & - \\
\hline 57 & beta-Terpineol & - & 0.079 & - & - & - & - \\
\hline 58 & $\begin{array}{l}\text { 2-Cyclohexen-1-ol, 1-methyl-4 } \\
\text {-(1-methylethyl)-.trans }\end{array}$ & - & 0.222 & - & - & - & - \\
\hline 59 & $\begin{array}{l}\text { 3,4-Dimethyl-1H-pyrrole-2- } \\
\text { carboxylic acid }\end{array}$ & - & 0.097 & - & - & - & - \\
\hline 60 & Phenol.4-amino & - & 0.208 & - & - & - & - \\
\hline 61 & $\begin{array}{l}\text { Succinic acid, di(3,5- } \\
\text { dimethylcyclohexyl) ester }\end{array}$ & - & 1.133 & - & - & - & - \\
\hline 62 & trans-alpha.-Bergamotene & - & 0.182 & - & - & - & - \\
\hline 63 & beta-Farnesene & - & 0.914 & - & - & - & - \\
\hline 64 & $\begin{array}{l}\text { Phenol,2,6-bis(1,1- } \\
\text { dimethylethyl)- }\end{array}$ & - & 0.162 & - & - & - & - \\
\hline 65 & cis-alpha,-Bisabolene & - & 0.09 & - & - & - & - \\
\hline 66 & Cyclohexane,ethylidene- & - & 0.077 & - & - & - & - \\
\hline 67 & (S)-cis-Verbenol & - & 0.343 & - & - & - & - \\
\hline 68 & $\begin{array}{l}\text { Silane,[[4-[1,2-bis } \\
\text { [(trimethylsilyl)oxy]ethyl]-1,2- } \\
\text { phenylene]bis(oxy)bis } \\
\text { [trimethyl- }\end{array}$ & - & $\begin{array}{c}0.226+ \\
0.070\end{array}$ & - & - & - & 0.093 \\
\hline 69 & $\begin{array}{l}\text { 1,1,1,5,7,7,7-Heptamethyl-3,3- } \\
\text { bis(trimethylsiloxy) } \\
\text { tetrasiloxane }\end{array}$ & - & 0.079 & - & - & - & 0.043 \\
\hline
\end{tabular}




\begin{tabular}{|c|c|c|c|c|c|c|c|}
\hline & Chemical compound & $C c$ & $\overline{C d}$ & $C l(1)$ & $C l(2)$ & $S G$ & $S W$ \\
\hline 70 & Cycloheptasiloxane,tetradecamethyl & - & 0.062 & - & - & - & - \\
\hline 71 & $\begin{array}{l}\text { Oxacyclotetradecan-2-one, } 1,3- \\
\text { methyl- }\end{array}$ & - & 0.106 & - & - & - & - \\
\hline 72 & Heptasiloxane, hexadecamethyl & - & 0.067 & - & - & - & 0.092 \\
\hline 73 & $\begin{array}{l}\text { Isobenzofuran-1(3H)-one,3-(3- } \\
\text { furyl)-3a,4,5,6-tetrahydro-3a,7- } \\
\text { dimethyl- }\end{array}$ & - & - & - & - & 0.094 & - \\
\hline 74 & $\begin{array}{l}\text { Bicyclo[4.2.0]octa-2,4-diene-7- } \\
\text { carbonitrile }\end{array}$ & - & - & - & - & 0.113 & - \\
\hline 75 & alpha-caryophyllene & - & - & - & 1.119 & 0.674 & - \\
\hline 76 & $\begin{array}{l}\text { Spiro[2,4]heptane,1,5-dimethyl-6- } \\
\text { methylene }\end{array}$ & - & - & - & - & 0.419 & - \\
\hline 77 & 2-Pentyn-1-ol & - & - & - & 0.117 & - & - \\
\hline 78 & (S)-Camphor & - & - & - & 0.36 & - & - \\
\hline 79 & L-Borneol & - & - & - & 0.354 & - & - \\
\hline 80 & Acetic acid, Borneol ester & - & - & - & 0.186 & - & - \\
\hline 81 & delta-Elemene & - & - & - & 3.363 & - & - \\
\hline 82 & 1S-alpha-Pinene & - & - & - & 1.486 & - & - \\
\hline 83 & 4-Amino-6-hydroxypyrimidine & - & - & - & 3.565 & - & - \\
\hline 84 & alpha-Cubebene & - & - & - & 0.922 & - & - \\
\hline 85 & beta-Cubebene & - & - & - & 2.471 & - & - \\
\hline 86 & gamma-Cadinene & - & - & - & 0.2 & - & - \\
\hline 87 & alpha-farnesene & - & - & - & 0.305 & - & - \\
\hline 88 & alpha-Cadinene & - & - & - & 0.114 & - & - \\
\hline 89 & Germacrene D & - & - & 2.279 & 8.338 & - & - \\
\hline 90 & Bicyclo[6.4.0]dodeca-9,11-diene & - & - & - & 0.222 & - & - \\
\hline 91 & Longifolene & - & - & - & 1.164 & - & - \\
\hline 92 & $\begin{array}{l}\text { 1R,3Z,9S-2,6,10,10- } \\
\text { Tetramethylbicyclo[7,2,0]undeca- } \\
\text { 2,6-diene }\end{array}$ & - & - & - & 0.619 & - & - \\
\hline 93 & $\begin{array}{l}\text { p-Cyanophenyl p-(2-butoxyethoxy) } \\
\text { benzoate }\end{array}$ & - & - & - & 0.189 & - & - \\
\hline 94 & $\begin{array}{l}\text { 1H-Indene,2,3,3a,4-tetrahydro- } \\
\text { 3,3a,6-trimethyl-1-(1-methylethyl)- }\end{array}$ & - & - & - & 0.145 & - & - \\
\hline 95 & $\begin{array}{l}\text { Naphthalene,1,2,4a,5,6,8a- } \\
\text { hexahydro-4,7-dimethyl-1-(1- } \\
\text { methylethyl)-,[1R- } \\
\text { (1.alpha.,4a.alpha.,8a.alpha.)]- }\end{array}$ & - & - & - & 0.146 & - & - \\
\hline 96 & $\begin{array}{l}\text { Carbonic acid, ethyl 2,2,2- } \\
\text { trichloroethyl ester }\end{array}$ & - & - & - & 0.233 & - & - \\
\hline 97 & 2,8-Decadiyne & - & - & - & 0.283 & - & - \\
\hline 98 & $\begin{array}{l}\text { Tricyclo[6.3.0.0(2,4)]undec-8- } \\
\text { ene,3,3,7,11-tetramethyl }\end{array}$ & - & - & - & 1.743 & - & - \\
\hline 99 & Isocaryophillene & - & - & - & 1.119 & - & - \\
\hline 100 & Undec-10-ynoic acid & - & - & - & 0.32 & - & - \\
\hline
\end{tabular}




\begin{tabular}{|c|c|c|c|c|c|c|c|}
\hline & Chemical compound & $C c$ & $\overline{C d}$ & $C l(1)$ & $\mathrm{Cl}(2)$ & $S G$ & $S W$ \\
\hline 101 & 4-Ethoxy-2-(methylamino)tropone & - & - & - & 0.641 & - & - \\
\hline 102 & gamma-Cadinene & - & - & - & $\begin{array}{c}0.826+ \\
2.189\end{array}$ & - & - \\
\hline 103 & alpha-Cadinol & - & - & - & 3.094 & - & - \\
\hline 104 & $\begin{array}{l}\text { [4,4-Bipyrimidine]-2,2,6 } \\
(1 \mathrm{H}, 1 \mathrm{H}, 3 \mathrm{H}) \text {-trione, } 5 \text {-methyl }\end{array}$ & - & - & - & 0.191 & - & - \\
\hline 105 & $\begin{array}{l}\text { Hydrazine,2-[fluorobis(1- } \\
\text { methylpropyl)silyl]-1,1-dimethyl- }\end{array}$ & - & - & - & 0.075 & - & - \\
\hline 106 & $\begin{array}{l}\text { Benzene,1-(5,5-dimethyl-1- } \\
\text { cyclopenten-1-yl)-2-methoxy- }\end{array}$ & - & - & - & 0.33 & - & - \\
\hline 107 & $\begin{array}{l}\text { Benzaldehyde,2-hydroxy-3-(2- } \\
\text { propenyl)- }\end{array}$ & - & - & - & 0.166 & - & - \\
\hline 108 & Ethanol,1-(2-benzimidazolyl)- & - & - & - & 0.222 & - & - \\
\hline 109 & 2,4-Dihydroxy-1,5-naphthyridine & - & - & - & 0.184 & - & - \\
\hline 110 & 7-Hexadecyn-1-ol & - & - & - & 0.095 & - & - \\
\hline 111 & 1,6-Octadecanoic acid, methyl ester & - & - & - & 0.554 & - & - \\
\hline 112 & $\begin{array}{l}\text { Bicyclo[3.3.0]octan-3-one,7- } \\
\text { ethylidene }\end{array}$ & - & - & - & - & - & 0.107 \\
\hline 113 & $\begin{array}{l}\text { 1,2,4-Triazolo[4,3-a]pyridin-3(2H)- } \\
\text { one, 5-methyl- }\end{array}$ & - & - & - & - & - & 0.198 \\
\hline 114 & Benzene, (2-methylpropoxy)- & - & - & - & - & - & 0.057 \\
\hline 115 & $\begin{array}{l}\text { 4,7,10,13,16,19-Docosahexaenoic } \\
\text { acid, methyl ester, (all-Z) }\end{array}$ & - & - & - & - & - & 0.078 \\
\hline 116 & 3-Ethylidenecycloheptane & - & - & - & - & - & 0.428 \\
\hline 117 & 2-Cyclohexen-1-one,4,4,6-trimethyl & - & - & - & - & - & 0.067 \\
\hline 118 & Cyclononasiloxane,octadecamethyl & - & - & - & - & - & 0.057 \\
\hline 119 & $(+)-4$-Carene & - & - & 0.169 & - & - & - \\
\hline 120 & beta-Cubebene & - & - & 0.663 & - & - & - \\
\hline 121 & Methyleugenol & - & - & 59.268 & - & - & - \\
\hline 122 & $\begin{array}{l}\text { Bicyclo[7,2,0] undec-4-ene, } 4,11,11 \text { - } \\
\text { trimethyl-8-methylene }\end{array}$ & - & - & 1.738 & - & - & - \\
\hline
\end{tabular}

terpineol, $4.58 \%$ of alpha-santalene, $5.42 \%$ of 4-terpineol and $3.41 \%$ of linalool. The highest chemical constituent in two $\mathrm{Cl}$ (1) and (2) plants varied as methyl eugenol $(59.27 \%)$ in one plant and linalool $(30.93 \%)$ in the other. There were $7.16 \%$ of linalool, $24.99 \%$ of eugenol, $2.24 \%$ of copaene and $2.28 \%$ of germacrene $\mathrm{D}$ in $\mathrm{Cl}$ (1). $\mathrm{Cl}$ (2) contained $10.01 \%$ of alpha-terpineol, $3.04 \%$ of caryophyllene and $8.34 \%$ of germacrene D. $\mathrm{Cl}$ plants at the same location exhibited a variation in their leaf essential oil composition. According to Kumarathilake (2009), the essential oil extracted from $C c$ leaves from Walakanda forest possessed $90.25 \%$ of eugenol and $5.98 \%$ of linalool. Kumarathilake (2009) reported the in-situ chemical compositional variation of four $C d$ leaf essential oil samples: two samples from
Gongala forest reserve (G1 and G2), one from Rakwana and one from Hay's Group Estate. All four samples contained citral $-b$ as the major chemical compound of $C d$ leaf essential oil. There was $27.43 \%$ of cinnamyl alcohol with $29.51 \%$ citral-b in G1. G2 reported the presence of $21.21 \%$ of citral-b, $16.65 \%$ of $\beta$ caryophyllene and $13.77 \%$ of eucalyptol. According to Kumarathilake (2009), Cd plants from the same location exhibited a variation of leaf essential oil composition. $C d$ leaf oil from Rakwana contained $18.57 \%$ of citral-b, $16.08 \%$ of cinnamyl alcohol and $16.52 \%$ of myrcene, while $35.8 \%$ of citral-b, $28.18 \%$ of cinnamyl alcohol and $10.91 \%$ of linalool were present in $C d$ leaf oil sample from Hay's group. Leaf essential oil of $\mathrm{Cl}$ and $C d$ from the Western Ghats, India contained $32.1 \%$ of alpha-phellandrene and $64.6 \%$ of 
caryophyllene oxide respectively (Ananthakrishnan et al. 2018).

\section{CONCLUSION}

There was a variation in leaf morphological characters in $\mathrm{Cc}, \mathrm{Cd}, \mathrm{Cl}, \mathrm{SG}$ and $\mathrm{SW}$. The observed $C l$ plant was of type $\mathrm{A}$ and $C d$ was of type B. Partial overlapping of functional male and female phases should be further investigated to determine the possibility of self-pollination. Eugenol was the major chemical compound of leaf essential oils from Cc (33.11\%). Eucalyptol was the major chemical compound of $C d(51.19 \%)$. The highest chemical constituent in two $\mathrm{Cl}$ plants varied as methyl eugenol $(59.27 \%)$ in one plant and linalool $(30.93 \%)$ in the other. This information signifies the necessity of understanding the variation within a spp. and identification of chemotypes.

\section{AUTHOR CONTRIBUTION}

MRP, RAAKR and SG conceptualized and designed the study. MRP performed the experiments and analyzed the data. MRP, SAR and SG interpreted the data. MRP and SG drafted the manuscript. RAAKR and SG critically revised the manuscript.

\section{References}

Abeysekera WPKM, Arachchige, SPG and Ratnasooriya WD 2017 Bark extracts of Ceylon cinnamon possess antilipidemic activities and bind bile acids in-vitro. Evidence-Based Complementary and Alternative Medicine: 1-10.

Ananthakrishnan R, Santhosh Kumar ES and Rameshkumar KB 2018 Comparative Chemical Profiles of Essential Oil Constituents of Eight Wild Cinnamomum Species from the Western Ghats of India. Natural Product Communications, 13(5): 621625.

Azad R, Jayasekara L, Ranawaka RAAK, Senanayaka G, Kumara KLW, Pushpakumara DKNG and Geekiyanage S 2019a Development of a core collection for Sri Lankan cinnamon germplasm based on morphological characterization using an eco-geographical survey. Australian Journal of Crop Science. 13(9): 1473 1485.

Azad R, Kumara KW, Senanayake G, Ranawaka RAAK, Pushpakumara DKNG and Geekiyanage S 2019b Intensity of leaf spot and rough bark diseases in cinnamon accessions collected from major cinnamon growing areas of Sri Lanka. Journal of the National Science Foundation of Sri Lanka, 47(3): 297-305.

Azad R, Kumara KW, Senanayake G, Ranawaka RAAK, Pushpakumara DKNG and Geekiyanage S 2018 Flower morphological diversity of cinnamon (Cinnamomum verum Presl) in Matara District, Sri Lanka. Open Agriculture, 3(1): 236-244.

Azad R, Ranawaka RAAK, Senanayake G, Kumara KW, Pushpakumara DKNG, Wijesinghe KGG and Geekiyanage S 2016 Morphological variation of cinnamon (Cinnamomum verum Persl) germplasm in Matara District of Sri Lanka. International Journal of Minor Fruits, Medicinal and Aromatic Plants, 2(1): 6-14.

Azad R, Senanayake G, Kumara KLW, Ranawaka RAAK, Pushpa-Kumara DKNG, Wijesinghe KGG and Geekiyanage S 2015 Morphological variation within progeny and deviations from mother plant reveal the allele richness in Cinnamomum verum germ-plasm: a case study from Deiyandara, Matara collection at the early vegetative stage. Tropical Agricultural Research and Extension, 18(4):163-167.

Geethakumary MP, Kumar ESS, Pandurangan AG and Shaju T 2007 Cinnamomum dubium Nees (Lauraceae) - A new record for India. Indian Journal of Forest, 30: 73-74.

Geethakumary MP, Pandurangan AG and Kumar ES 2012 Cinnamomum litseaefolium (Lauraceae)-A new distributional record for India. Rheedea, 22(2):127-130.

Gulcin I, Kaya R, Goren AC, Akincioglu H, Topal M, Bingol Z, Cetin Çakmak K, 
Ozturk Sarikaya SB, Durmaz L and Alwasel S 2019 Anticholinergic, antidiabetic and antioxidant activities of cinnamon (Cinnamomum verum) bark extracts: polyphenol contents analysis by LC-MS/MS. International Journal of Food Properties, 22(1):1511 $-1526$.

Heslop-Harrison Y and Shivanna KR 1977 The receptive surface of the angiosperm stigma. Annals of Botany. 41(6):1233-1258.

Ho KY and Hung TY 2011 Cladistic relationships within the genus Cinnamomum (Lauraceae) in Taiwan based on analysis of leaf morphology and inter-simple sequence repeat (ISSR) and internal transcribed spacer (ITS) molecular markers. African Journal of Biotechnology, 10(24):4802 $-4815$.

Ho KY, Lee SC, Shiue SW and Hwang CC 2015 A comparison of nrDNA internal transcribed spacer (ITS) loci for phylogenetic inference and authentication among Cinnamomum osmophloeum and related species in Taiwan. African Journal of Biotechnology, 14(13):1088-1096.

Joseph J 1981 Floral biology and variation in cinnamon. In S. Vishveshwara (ed.) Proc. PLACROSYM $\square, \quad$ ISPC, CPCRI, Kasaragod, India, pp.431-434.

Kim JR, Jeong IH, Lee YS and Lee SG 2015 Insecticidal activity of cinnamon essential oils, constituents, and (E)cinnamaldehyde analogues against Metcalfa pruinosa Say (Hemiptera: Flatidae) nymphs and adults. Korean Journal of Applied Entomology, 54(4), pp.375-382.

Kumarathilake DMHC 2009 Study on the Extinction Risks, Conservation and Domestication of Endemic Wild Cinnamon Species in Sri Lanka. M. Phill thesis, Department of Agricultural Biology, Faculty of Agriculture, University of Ruhuna. Kamburupitiya.

Kumarathilake DMHC, Senanayake SGJN, Wijesekera GAW, Wijesundera DSA and Ranawaka RAAK 2010 Extinction risk assessment at the species level: national red list status of endemic wild cinnamon species in Sri Lanka. Tropical Agricultural Research. 21(3): 247-257.

Kubitzky K and Kurz H 1984 Synchronized dichogamy and dioecy in neotropical Lauraceae. Plant Systematics and Evolution, 147:253-266.

Kumari HRSN, Wijesinghe KGG and Ranawaka RAAK 2008 Study on floral behavior of selected ten cultivars of true cinnamon Cinnamomum verum (Presl), Syn. $C$. zeylanicum (Blume), Proceedings of the National Symposium, Sri Lanka. 2008, pp. 29.

Mabberley DJ 2008 Mabberley's plant-book: a portable dictionary of plants, their classifications and uses. 3rd edition. Cambridge University Press.

Mohanakumar GN, Mokashi AN, Narayana Swamy P, Prabhakar N, Devar KV, Reddy DNR and Nalawadi UG 1985 Studies on the floral biology of Cinnamon. Indian Cocoa, Arecanut and Spices Journal. 8(4):100-102.

Paranagama PA, Wimalasena S, Jayatilake GS, Jayawardena AL, Senanayake UM and Mubarak AM 2001 A comparison of essential oil constituents of bark, leaf, root and fruit of cinnamon (Cinnamomum zeylanicum Blum) grown in Sri Lanka. Journal of the National Science Foundation of Sri Lanka, 29(3-4): 147 $-153$.

Plants of the World Online [Online] Available at: $<$ http:// www.plantsoftheworldonline.org/ taxon $>$ [Accessed 24 February 2021].

Prathibhani MR, Azad R and Geekiyanage S 2020 Variation of shoot regeneration capacity of cuttings of selected Cinnamomum verum genotypes. International Journal of Minor Fruits, Medicinal and Aromatic Plants. 6(1): 20-24.

Prathibhani MR, Azad R, Ranawaka RAAK, Abeynayake S, Samaraweera DN and Geekiyanage S 2019 Variation of leaf morphology and leaf chemical 
composition of a Cinnamomum verum collection from Sri Lanka. Proceedings of Young Graduate's Forum, International Symposium on Agriculture and Environment (2019), Faculty of Agriculture, University of Ruhuna, Matara, Sri Lanka. pp-2.

Ravindran PN, Nirmal-Babu K and Shylaja M, eds 2004 Cinnamon and cassia: the genus Cinnamomum. CRC press.

Ranasinghe P and Galappaththy P 2016 Health benefits of Ceylon cinnamon (Cinnamomum zeylanicum): a summary of the current evidence. Ceylon Medical Journal, 61 (1): 1-5.

Ranasinghe P, Perera S, Gunatilake M, Abeywardene E, Gunapala N, Premakumara S, Perera K, Lokuhetty D and Katulanda P 2012 Effects of Cinnamomum zeylanicum (Ceylon cinnamon) on blood glucose and lipids in a diabetic and healthy rat model. Pharmacognosy Research, 4 (2):73-74.

Schaffer B and Andersen PC 2018 Handbook of Environmental Physiology of Fruit Crops. CRC Press.

Sedgley M 1985 Some effects on daylength and flower manipulation on the floral cycle of two cultivars of avocado (Persea americana Mill. Lauraceae) a species showing protogynous dichogamy. Journal of Experimental Botany, 36(5):823-832.

Sedgley M and Griffin AR 1989 Sexual Reproduction of Tree Crops. Academic Press, New York.

Senanayake UM and Wijesekera ROB 1989 The volatiles of the Cinnamomum species. In Proceedings of the $11^{\text {th }}$ International Congress of essential oils, fragrances and flavours. New Delhi, India, 12-16 November, Chemistry-Analysis and Structure. 4: 103-120.

Team of TURIS 2013 project 2016. Descriptors for Cinnamon (Cinnamomum verum). University of Ruhuna, Matara, Sri Lanka. ISBN 978 -955-1507-49-7:30-40.

Toriizuka K 1998 Basic lecture of Kampo medicine: pharmacological effect of cinnamon. Kampo Med., 11, pp. 431436.

Unlu M, Ergene E, Unlu GV, Zeytinoglu HS and Vural N 2010 Composition, antimicrobial activity and in-vitro cytotoxicity of essential oil from Cinnamomum zeylanicum Blume (Lauraceae). Food and Chemical Toxicology, 48(11): 3274-3280.

Yang HW, Hsu HC, Yang CK, Tsai MJ and Kuo YF 2019 Differentiating between morphologically similar species in genus Cinnamomum (Lauraceae) using deep convolutional neural networks. Computers and Electronics in Agriculture, 162:739-748.

Zeng G, Liu B, Ferguson DK, Rohwer JG and Yang Y 2017 Floral structure and ontogeny of Syndiclis (Lauraceae). PloS one, 12(10): p.e0186358. 